\title{
Technical note: Evaluation of a novel enzymatic method to predict in situ undigested neutral detergent fiber of forages and nonforage fibrous feeds
}

\author{
A. Gallo, ${ }^{*}$ S. Bruschi, and F. Masoero \\ Department of Animal Science, Food and Nutrition (DIANA), Faculty of Agricultural, Food and Environmental Sciences, \\ Università Cattolica del Sacro Cuore, 29122 Piacenza, Italy
}

\section{ABSTRACT}

The purpose of this study was to optimize the conditions of a previously proposed enzymatic method used to estimate in situ undigested neutral detergent fiber (uNDF). We used a multi-step enzymatic approach, in which samples were first solubilized in $\mathrm{NaOH}$ solutions as a preincubation (PreInc) phase. After rinsing, samples were incubated $\left(24 \mathrm{~h}\right.$ at $\left.39^{\circ} \mathrm{C}\right)$ in a buffered solution ( $\mathrm{pH}$ 6) containing hemicellulase, cellulase, and Viscozyme L enzymes (Sigma-Aldrich s.r.l., Milan, Italy), followed by incubation $\left(24 \mathrm{~h}\right.$ at $\left.39^{\circ} \mathrm{C}\right)$ in a buffered solution ( $\mathrm{pH} 5)$ containing xylanase. Two sets of experiments were performed: a calibration trial (that tested different PreInc conditions on 9 selected forages) and a validation trial (that verified the results by testing multiple samples of 6 different forage types and a group of fibrous by-products). In the calibration trial, samples (300 mg in Ankom F57 filter bags; Ankom Technology Corp., Fairport, NY) were preincubated at $39^{\circ} \mathrm{C}$ in a $0.1 \mathrm{M} \mathrm{NaOH}$ solution for 90,180 , or $240 \mathrm{~min}$, or in $0.2,0.5,1.0$, or $2.0 \mathrm{M} \mathrm{NaOH}$ solution for $90 \mathrm{~min}$. The results indicated that the best PreInc method, in terms of intra-laboratory repeatability and estimation of reference in situ values, was $90 \mathrm{~min}$ in a $0.2 \mathrm{M} \mathrm{NaOH}$ solution. Thus, we used this PreInc condition to determine enzymatic uNDF of 257 samples in the validation trial. Although the selected method generally had good accuracy in predicting in situ uNDF, inconsistencies were noted for certain forage types. Overall, when enzymatic uNDF was used to predict the in situ uNDF of all samples, the regression was satisfactory (intercept $=$ 7.098 , slope $\left.=0.920, R^{2}=0.73\right)$. The regression models developed for alfalfa hays, corn silages, and small grain silages had also acceptable regression performances and mean square error of prediction (MSEP) values, and the main sources of MSEP variation were error due to incomplete (co)variation and random error. Even when

Received January 10, 2019.

Accepted March 6, 2019.

*Corresponding author: antonio.gallo@unicatt.it
$\mathrm{R}^{2}$ values were $>0.70$, the MSEP value of the regression model for grass hays was 149.55, and that for nonforage fibrous feeds was 155.16. Although enzymatic uNDF partially overestimated the in situ uNDF, particularly in grass silages, the proposed procedure seems to be promising for accurately predicting in situ uNDF, because it generally had good repeatability and provided satisfactory estimates of in situ uNDF.

Key words: silage, indigestible neutral detergent fiber, in vitro method, nutritional model

\section{Technical Note}

Indigestible neutral detergent fiber (iNDF) is a digestibility parameter widely used to characterize the nutritional value of forages and other fibrous livestock feeds (Krämer et al., 2012; Van Amburgh et al., 2015). By definition, the iNDF is the fraction of NDF that remains undigested by rumen microorganisms after an infinite time and it is used to quantify, by difference, the potentially digestible fiber fraction (Mertens, 2016; Palmonari et al., 2016). Researchers commonly use the amount of undigested NDF (uNDF) after 120, 240, or more hours of rumen incubation to estimate iNDF, the latter being unmeasurable by definition (Mertens, 2016). Previous researchers used uNDF for its ability to properly predict OM digestibility (Nousiainen et al., 2003; Huhtanen et al., 2006), as an internal marker for total-tract digestibility (Lee and Hristov, 2013), as an indicator of ruminal passage rate and digestion kinetics (Krizsan et al., 2012), as a measure of the energy content of different forages (Gallo et al., 2013), or to assess the rumen fill effect and its effect on DMI by ruminants (Fustini et al., 2017).

However, uNDF is difficult to measure in normal laboratory practice because it requires access to rumen fluid and very long incubation times (Bender et al., 2016). It can be predicted by multiplying lignin content (Raffrenato et al., 2018) or it can be evaluated by adopting in vitro (Palmonari et al., 2016; Raffrenato et al., 2018) or in situ (Rinne et al., 2006; Krämer et al., 2012) rumen-based methods. The use of near infrared 
reflectance spectroscopy (NIRS) has also been investigated (Brogna et al., 2018). Although NIRS is suitable for indirect estimates of uNDF, calibrations (based on multivariate regression techniques) are needed, which decreases the accuracy and precision of this technique because of introduction of a prediction error.

Our previous work (Gallo et al., 2017) described a multi-step enzymatic method to estimate the in situ rumen NDF degradability (NDFD) of several feeds routinely given to dairy cows in northern Italy. We obtained satisfactory performance using the multi-step enzymatic method to predict in situ NDFD for rumen incubation times of 24 to $72 \mathrm{~h}$. However, the method produced unsatisfactory results when the incubation times were short (6 to $18 \mathrm{~h}$ ) or long (96 to $240 \mathrm{~h}$ ). Consequently, the multi-step enzymatic approach proposed by Gallo et al. (2017) needed to be enhanced for estimation of uNDF. Thus, the purpose of the present study was to extend the applicability of the previous multi-step enzymatic method by optimizing methodology used to estimate in situ uNDF.

To do this, samples were selected and used in 2 consecutive experiments. The first experiment (calibration trial) was designed to find the optimal conditions for the multi-step enzymatic method in estimating in situ uNDF; the second experiment (validation trial) was designed to test the optimal enzymatic condition on different types of forages collected during different years and from different locations. In particular, the calibration trial used 9 samples previously tested by Gallo et al. (2017): 1 alfalfa hay, 1 beet pulp, 2 corn silages, 1 distillers dried grains with solubles (DDGS), 1 meadow hay, 1 soybean hull, 1 soft white wheat bran, and 1 wheat straw. These samples were selected to cover a wide range in uNDF values, and they were collected in northern Italy or provided by Cargill s.r.l Divisione Feed \& Nutrition (Fiorenzuola d'Arda, Piacenza, Italy). Then, the validation trial compared the in situ and optimized enzymatic methods with results from a database on 61 alfalfa hays, 49 grass hays, 65 corn silages, 52 small grain silages, 17 sorghum silages, and 13 nonforage fibrous feeds. Some of these samples were collected during the 2009 to 2013 harvest seasons and were previously presented (Gallo et al., 2013, 2016, 2017). Other samples were randomly selected among samples sent to the laboratory of the Department of Animal Science, Food and Nutrition (Faculty of Agricultural, Food and Environmental Sciences, Università Cattolica del Sacro Cuore, Piacenza, Italy) for routine analysis and were presumably collected from the 2011 to 2015 harvest seasons.

Samples were ground using a cutter mill (1-mm screen, Pulviresette 19; Fritsch, Idar-Oberstein, Germany) and analyzed for DM using method 945.15 (AOAC Inter- national, 1995). The neutral detergent, acid detergent, and sulfuric acid lignin fiber fractions were quantified using the Ankom ${ }^{\text {II }}$ Fiber Analyzer (Ankom Technology Corp., Fairport, NY; Van Soest et al., 1991). The neutral detergent solution contained sodium sulfite and a heat-stable amylase. Fiber fractions were corrected for residual ash content (aNDFom and ADFom).

\section{In Situ Undigested NDF Evaluation}

The in situ uNDF (expressed as percentage on a DM basis) was determined using 2 rumen-cannulated dry Holstein dairy cows (BW: $625 \pm 10 \mathrm{~kg}$ ) fed maintenance feed (NRC, 2001) with a TMR (120 g/ kg of CP and $550 \mathrm{~g} / \mathrm{kg}$ of aNDFom on a DM basis) that consisted of $250 \mathrm{~g} / \mathrm{kg}$ of alfalfa hay, $450 \mathrm{~g} / \mathrm{kg}$ of grass hay, $150 \mathrm{~g} /$ $\mathrm{kg}$ of corn silage, $50 \mathrm{~g} / \mathrm{kg}$ of beet pulp, and $100 \mathrm{~g} / \mathrm{kg}$ of a protein-vitamin-mineral supplement. The diet was administered to the cows twice a day, at 0800 and 1800 h. Animal care followed the guidelines of the European Commission Council Directive.

Ground samples $(\sim 300 \mathrm{mg})$ were inserted into acetone-prewashed polyester or polyethylene filter bags (Ankom F57, 2 bags per sample/cow, $25 \mu \mathrm{m}$ porosity, sample size per net surface area $=\sim 10 \mathrm{mg} / \mathrm{cm}^{2}$; Vanzant et al., 1998) that were within string-net bags $(10 \times 15 \mathrm{~cm}, 15-\mathrm{mm}$ pore size, 2 filter bags each $)$, as described by Spanghero et al. (2010) with slight modifications. The in situ rumen incubation time was 240 h. Each sample was incubated in the rumen of 2 cows and incubation was repeated once. At the end of rumen incubation, bags were rinsed in a household washing machine (3 washes of 2.5 min each, 2 with cold water, and the last with distilled water; Smeg GW 3000, Smeg Instruments Division, Guastalla, Italy), and then dried at $55^{\circ} \mathrm{C}$. The residual aNDFom was determined for the dried bags as reported above. Bags inserted into the rumen of a single cow were considered analytical repetitions; bags inserted into 2 different cows were considered experimental replicates.

\section{Multi-Step Enzymatic Method Procedures}

The multi-step enzymatic method consisted of a preincubation phase (PreInc), followed by 2 successive enzymatic steps, as previously described (Gallo et al., 2017). The following 7 PreInc conditions were tested in the calibration trial (300-mg samples in Ankom F57 filter bags at $39^{\circ} \mathrm{C}$ ): incubation in a $0.1 \mathrm{M}$ $\mathrm{NaOH}$ solution for 90, 180, or $240 \mathrm{~min}$ (90-PreInc$\mathbf{0 . 1} M, \mathbf{1 8 0}$-PreInc-0.1 $M$, or 240-PreInc-0.1 $M$ ) or incubation for $90 \mathrm{~min}$ in solutions of $0.2,0.5,1.0$, or $2.0 M \mathrm{NaOH}$ (90-PreInc-0.2 $\boldsymbol{M}$, 90-PreInc-0.5 $\boldsymbol{M}$, 90-PreInc-1.0 $M$, or 90-PreInc-2.0 $M$ ). Each bag 
was first put into different glass beakers as a function of the corresponding condition of PreInc; then, the specific $\mathrm{NaOH}$ concentrated solution was added at a ratio of $15 \mathrm{~mL} / \mathrm{bag}$ and shaken for $10 \mathrm{~min}$ to let the solution properly drench the bags. Finally, the bags were rinsed with distilled water until the wash water had a neutral $\mathrm{pH}(\sim 15-20$ washes $)$.

The water-washed bags were then reused to perform the 2 successive steps of enzyme incubations. First, a buffer solution $(3.56 \mathrm{~g} / \mathrm{L}$ potassium phosphate and 5.77 $\mathrm{g} / \mathrm{L}$ of sodium phosphate; Sigma-Aldrich s.r.l., Milan, Italy) was prepared and adjusted to $\mathrm{pH} 6.0$ using orthophosphoric acid $\left(0.85 \mathrm{wt} / \mathrm{wt}\right.$ in $\left.\mathrm{H}_{2} \mathrm{O}\right)$. Then, Aspergillus niger hemicellulase (4 g/L, Sigma-Aldrich s.r.l.), Trichoderma viride cellulase $(10 \mathrm{~g} / \mathrm{L}, \mathrm{BDH}$ Chemicals Ltd., Poole, UK), and Viscozyme L (10 mL/L, SigmaAldrich s.r.l.) were added, and the solution was gently stirred for $60 \mathrm{~min}$. Each water-washed bag $(15 \mathrm{~mL} /$ bag) was then placed into a glass beaker and incubated at $39^{\circ} \mathrm{C}$ for $24 \mathrm{~h}$ in the buffered enzyme solution. The bags were then removed and washed with water, as previously described for PreInc.

After the first incubation step, Thermomyces lanuginosus xylanase (2 g/L, Sigma-Aldrich s.r.l.) was added to the freshly prepared buffer, as detailed above except for the $\mathrm{pH}$, which was adjusted to 5.0. Then, each bag was placed into a glass beaker and incubated with the buffered enzymatic solution $(15 \mathrm{~mL} / \mathrm{bags})$ at $39^{\circ} \mathrm{C}$ for a further $24 \mathrm{~h}$. The bags were rinsed with distilled water and dried at $55^{\circ} \mathrm{C}$, and the residual aNDFom was determined as described earlier.

The PreInc method that provided the best estimates of in situ uNDF in the calibration trial (90-PreInc$0.2 M$ ) was used for all silages, hays, nonforage fibrous feeds, and crop residues in the validation trial. The enzymatic methods were used to test each sample in duplicate on 2 different days.

The results of chemical assays, in situ uNDF measurements, and enzymatic uNDF measurements of the 9 samples in the calibration trial and of the 257 samples in the validation trial are presented descriptively (mean \pm standard deviations). The performance parameters of the enzymatic method [intra-laboratory repeatability, regression parameters for estimating in situ evaluated uNDF, and sources of variation of the mean square errors of prediction (MSEP)] were calculated. In particular, the intra-laboratory precision values were obtained by calculating the standard deviation of differences between repeated measurements $\left(\mathbf{s}_{\mathbf{r}}\right)$ of experimental replicates and the coefficients of variation of $\mathbf{s}_{\mathrm{r}}\left(\mathbf{R s}_{\mathrm{r}}\right.$; Spanghero et al., 2010). The precision was evaluated for all methods used in the calibration trial on each of the 9 samples or for 90-PreInc-0.2M method in the validation trial on each of 257 samples, either among or within forage types. The REG procedure of SAS (SAS Institute, 2003) was used to obtain regression parameters (intercept, slope, $\mathrm{R}^{2}$, and MSEP), using in situ uNDF as the independent variable and enzymatic uNDF as the dependent variable. The coefficients of determination and the mean square errors of prediction (MSEP) were used to evaluate the accuracy of the estimates of uNDF. In particular, the MSEP was partitioned into error in central tendency, error due to unequal variation, error due to incomplete (co)variation, systematic error, and random error, as suggested by Tedeschi (2006). Regression terms were considered significant for $P$-values below 0.05 .

Table 1 shows the fiber fractions and in situ uNDF of each feed examined in this study. The 9 samples tested in the calibration trial had aNDFom contents ranging from $38.7 \%$ of DM (corn silage 1) to $77.1 \%$ of DM (wheat straw). The ADFom content was $<30.0 \%$ of DM in beet pulp, corn silages, and wheat bran. The uNDF content of the 3 fibrous co-products (beet pulp, DDGS, and soybean hulls) was $<7.0 \%$ of DM. Intermediate uNDF values were found for the 2 corn silages (10.0 and $9.4 \%$ of DM), meadow hay ( $14.7 \%$ of DM), and wheat bran $(11.7 \%$ of DM), but uNDF values were $>30.0 \%$ of DM in alfalfa hay and wheat straw.

For samples tested in the validation trial, aNDFom was numerically lower in alfalfa hays ( $48.5 \%$ of DM) and corn silages ( $46.5 \%$ of $\mathrm{DM})$ than in grass hays (61.9\% of DM), small grain silages $(62.3 \%$ of DM), and sorghum silages ( $68.9 \%$ of DM). Intermediate aNDFom values were found for the fibrous co-products $(51.1 \%$ of DM). Measurements of uNDF indicated that corn silages had the lowest level $(12.2 \%$ of DM). The small grains $(23.9 \%$ of DM), sorghum silages (19.3\% of DM), and fibrous co-products (21.5\% of DM) had intermediate levels, whereas alfalfa (29.9\% of DM) and grass hays $(31.2 \%$ of DM) had the highest levels.

Table 2 shows the results from use of different enzymatic methods to estimate in situ uNDF of 9 selected feeds. In particular, the methods differed in the duration of preincubation in a $0.1 \mathrm{M} \mathrm{NaOH}$ solution or in the concentration of $\mathrm{NaOH}$ used during the PreInc step. As expected, the uNDF values were numerically lower as the concentration of $\mathrm{NaOH}$ solution increased from 0.1 to $2.0 \mathrm{M}$ and as the duration of $0.1 \mathrm{M} \mathrm{NaOH}$ pretreatment increased, although beet pulp had an inconsistent trend. Different methods showed high repeatability, the differences between analytical replicates being small and characterized by $\mathrm{s}_{\mathrm{r}}$ ranging from 1.21 (90-PreInc- $0.2 M)$ to 2.52 (180-PreInc-0.1 $M$ ). The standard deviations of $\mathrm{s}_{\mathrm{r}}$ were acceptable $(<15 \%)$ for 90-PreInc-0.1M, 180-PreInc-0.1M, 240-PreInc-0.1M, and 90 -PreInc- $0.2 M$. Other enzymatic conditions had $\mathrm{Rs}_{\mathrm{r}}$ values $>20.0 \%$. When the enzymatic $\mathrm{uNDF}$ was 
used to estimate in situ uNDF, the greatest coefficient of determination $\left(\mathrm{R}^{2}=0.89\right)$ was for $90-$ PreInc-0.2M. Moreover, the regression terms appeared satisfactory, intercepts being nonsignificant $(P>0.05)$ and slopes close to 1.0. The regression coefficients were $<0.70$ for all enzymatic conditions except 240-PreInc-0.1M $\left(\mathrm{R}^{2}\right.$ $=0.70)$ and 90 -PreInc-0.2M $\left(\mathrm{R}^{2}=0.89\right)$. The smallest MSEP were for 240-PreInc-0.1 M (34.19) and 90-PreInc$0.2 M(11.36)$, and the worst MSEP values were calculated for 90-PreInc-1.0M (81.39) and 90-PreInc-2.0M (118.60). The decomposition of MSEP to determine sources of variation indicated that the 90 -PreInc- $0.2 M$ method was the most accurate in estimating in situ uNDF. In particular, this method had low values for error in central tendency (2.7\% of MSEP), error due to unequal variation (2.4\% of MSEP), and systematic error $(0.0 \%$ of MSEP), and the largest random error (97.3\% of MSEP).

Table 3 shows the results of using the 90 -PreInc- $0.2 \mathrm{M}$ method for estimating in situ uNDF of feed samples and different feed types. When this method was tested on all 257 samples, $\mathrm{R}^{2}$ was 0.73 , the intercept was 7.098 , and the slope was $0.920(P<0.05)$. Consequently, the in situ uNDF values were slightly underestimated relative to enzymatic measurements in most of the tested feedstuffs. We found numerically lower MSEP values when the enzymatic method was used to estimate in situ uNDF for alfalfa hays (56.28), corn silages (44.02), small grain silages (16.29), and sorghum silages (25.80). For these feed categories, the intercepts were all posi- tive and ranged from 3.627 (corn silages) to 12.824 (sorghum silages). The regressions slope of sorghum silages (0.377) differed significant from $1.0(P<0.05)$; the other slopes ranged from 0.889 (small grain silages) to 1.139 (corn silages). Consequently, the regression models had similar accuracy for alfalfa hays, corn silages, and small grain silages, whereas the worst allocation of MSEP was for sorghum silages. In particular, the regression model for sorghum silages had significant error due to unequal variation (52.9\% of MSEP), error due to incomplete (co)variation (38.5\% of MSEP), and systematic error ( $75 \%$ of MSEP). The MSEP was numerically greater when enzymatic measurements were used to estimate in situ uNDF in grass hays (149.55) and nonforage fibrous feeds (155.16), although almost satisfactory $\mathrm{R}^{2}$ were determined for grass hay (0.71) and nonforage fibrous feeds (0.79). For these 2 feed types, random error was the main source of variation of MSEP (64.2\% of MSEP for grass hays and $67.4 \%$ of MSEP for nonforage fibrous feeds).

The present study was limited because it was an intra-laboratory validation. Our next steps are to improve the accuracy of this method for all feed categories and to validate it in an inter-laboratory trial. Further, although in vivo digestibility should be considered the "gold standard," it is not possible to use this approach to determine the uNDF values of forages (Mertens, 2016). Thus, we decided to adopt an in situ uNDF evaluation (Spanghero et al., 2010; Gallo et al., 2017) that used Ankom filter bags. Our in situ approach for

Table 1. Chemical composition ${ }^{1}$ (\% of DM; means \pm SD) of samples tested in calibration and validation trials

\begin{tabular}{|c|c|c|c|c|c|c|}
\hline Sample & $\mathrm{N}$ & aNDFom & ADFom & Lignin(sa) & uNDF & Reference \\
\hline \multicolumn{7}{|l|}{ Calibration trial $^{2}$} \\
\hline Alfalfa hay & 1 & $59.1 \pm 2.1$ & $50.7 \pm 0.7$ & $11.6 \pm 0.7$ & $35.2 \pm 0.6$ & Gallo et al. (2017) \\
\hline Beet pulp & 1 & $41.2 \pm 1.2$ & $23.1 \pm 0.7$ & $4.4 \pm 1.4$ & $6.9 \pm 0.2$ & Gallo et al. (2017) \\
\hline Corn silage 1 & 1 & $38.7 \pm 2.0$ & $23.7 \pm 0.3$ & $3.6 \pm 0.8$ & $10.0 \pm 0.3$ & Gallo et al. (2017) \\
\hline Corn silage 2 & 1 & $55.7 \pm 0.7$ & $29.1 \pm 0.2$ & $4.2 \pm 0.6$ & $9.4 \pm 0.1$ & Gallo et al. (2017) \\
\hline $\mathrm{DDGS}^{3}$ & 1 & $38.8 \pm 0.8$ & $25.8 \pm 0.2$ & $4.9 \pm 0.1$ & $5.3 \pm 0.1$ & Gallo et al. (2017) \\
\hline Meadow hay & 1 & $62.9 \pm 0.1$ & $42.7 \pm 0.1$ & $6.2 \pm 0.5$ & $14.7 \pm 0.5$ & Gallo et al. (2017) \\
\hline Soybean hulls & 1 & $64.4 \pm 0.2$ & $52.0 \pm 0.3$ & $2.6 \pm 1.6$ & $3.3 \pm 0.1$ & Gallo et al. (2017) \\
\hline Wheat bran & 1 & $45.9 \pm 0.6$ & $15.5 \pm 0.1$ & $5.5 \pm 0.1$ & $11.7 \pm 0.2$ & Gallo et al. (2017) \\
\hline Wheat straw & 1 & $77.1 \pm 0.2$ & $57.7 \pm 0.9$ & $10.3 \pm 1.0$ & $31.1 \pm 0.3$ & Gallo et al. (2017) \\
\hline \multicolumn{7}{|l|}{ Validation trial $^{2}$} \\
\hline Alfalfa hays & 61 & $48.5 \pm 6.7$ & $35.8 \pm 4.4$ & $9.4 \pm 1.0$ & $29.9 \pm 9.1$ & $\begin{array}{l}\text { Gallo and Masoero }(2013,2017 \\
\left.\text { unpublished }^{4}\right)\end{array}$ \\
\hline Grass hays & 49 & $61.9 \pm 5.2$ & $37.8 \pm 3.8$ & $7.9 \pm 2.9$ & $31.2 \pm 10.8$ & Gallo and Masoero $(2013,2017$, unpublished) \\
\hline Corn silage & 65 & $46.5 \pm 4.7$ & $24.3 \pm 3.4$ & $3.5 \pm 0.9$ & $12.2 \pm 8.9$ & Gallo and Masoero (2013, 2016, unpublished) \\
\hline Small grain silage & 52 & $62.3 \pm 5.8$ & $39.2 \pm 4.3$ & $6.2 \pm 0.9$ & $23.9 \pm 8.9$ & Gallo and Masoero (2013, unpublished) \\
\hline Sorghum silage & 17 & $68.9 \pm 4.5$ & $40.1 \pm 4.2$ & $5.7 \pm 0.8$ & $19.3 \pm 3.3$ & Gallo and Masoero (2013, unpublished) \\
\hline Fibrous co-products & 13 & $51.1 \pm 13.3$ & $30.9 \pm 9.7$ & $8.9 \pm 6.7$ & $21.5 \pm 16.3$ & Gallo and Masoero (2017, unpublished) \\
\hline
\end{tabular}

${ }^{1}$ aNDFom $=$ NDF assayed with a heat-stable amylase and exclusive of residual ash; ADFom $=$ ADF exclusive of residual ash; Lignin(sa) $=$ lignin sulfuric acid; $\mathrm{uNDF}=$ undigested NDF evaluated in situ after $240 \mathrm{~h}$ of rumen incubation.

${ }^{2}$ The standard deviations (SD) of means reported for feeds analyzed in calibration trial refer to differences between analytical replicates of the same sample. The SD of the means reported for feeds analyzed in the validation trial refer to differences among samples.

${ }^{3}$ Distillers dried grains with solubles.

${ }^{4}$ Unpublished data by A. Gallo and F. Masoero. 
evaluation of feed degradability followed the guidelines of Vanzant et al. (1998), even if the adoption of these bags and their related characteristics (i.e., bag material, pore size, or sample size to bag surface area ratio) could strongly influence in situ measurement. However, the use of solubilized enzymes could overcome problems associated with bag material and pore size. The scientific community has not yet agreed on the optimal conditions needed to measure the uNDF of feedstuffs (Krizsan et al., 2012; Bender et al., 2016; Raffrenato et al., 2018), and there is not yet a standardized methodology.

Many previous studies have used enzymatic approaches to predict the digestibility or degradability of livestock feeds, by using a single enzyme or a mixture of commercially available enzymes. Recently, Kowalski et al. (2014) examined the reliability of an in vitro method using cellulase from Trichoderma viride and filter bags with the Ankom Daisy Incubator system to estimate the in vivo digestibility of organic matter of several forages. Colombatto et al. (1999) tested the applicability of enzyme mixtures (cellulase and hemicellulase) to characterize the rumen degradability profiles of maize silage and alfalfa hay. Those authors concluded that their enzyme mixtures had the potential to describe the DM degradability profiles of the 2 tested forages, and they recommended further research to determine the optimal enzyme mixture.

To the best of our knowledge, the research presented here describes the first use of an enzymatic approach to directly estimate uNDF. The foundation for these studies was our previous paper (Gallo et al., 2017), in which the use of Ankom filter bags to incubate samples, the adoption of an alkaline preincubation procedure to solubilize samples before enzymatic hydrolysis, and the selection of specific enzymes (hemicellulase from Aspergillus niger, cellulase from Trichoderma viride, Viscozyme L, and xylanase from Thermomyces lanugi-

Table 2. Repeatability, regression parameters, and sources of variation of mean square errors of prediction $\left(\mathrm{MSEP}^{\%}\right.$ of DM $\left.{ }^{2}\right)$ for different preincubation procedures used before the multi-step enzymatic procedure for estimation of in situ undigested NDF (uNDF, \% of DM)

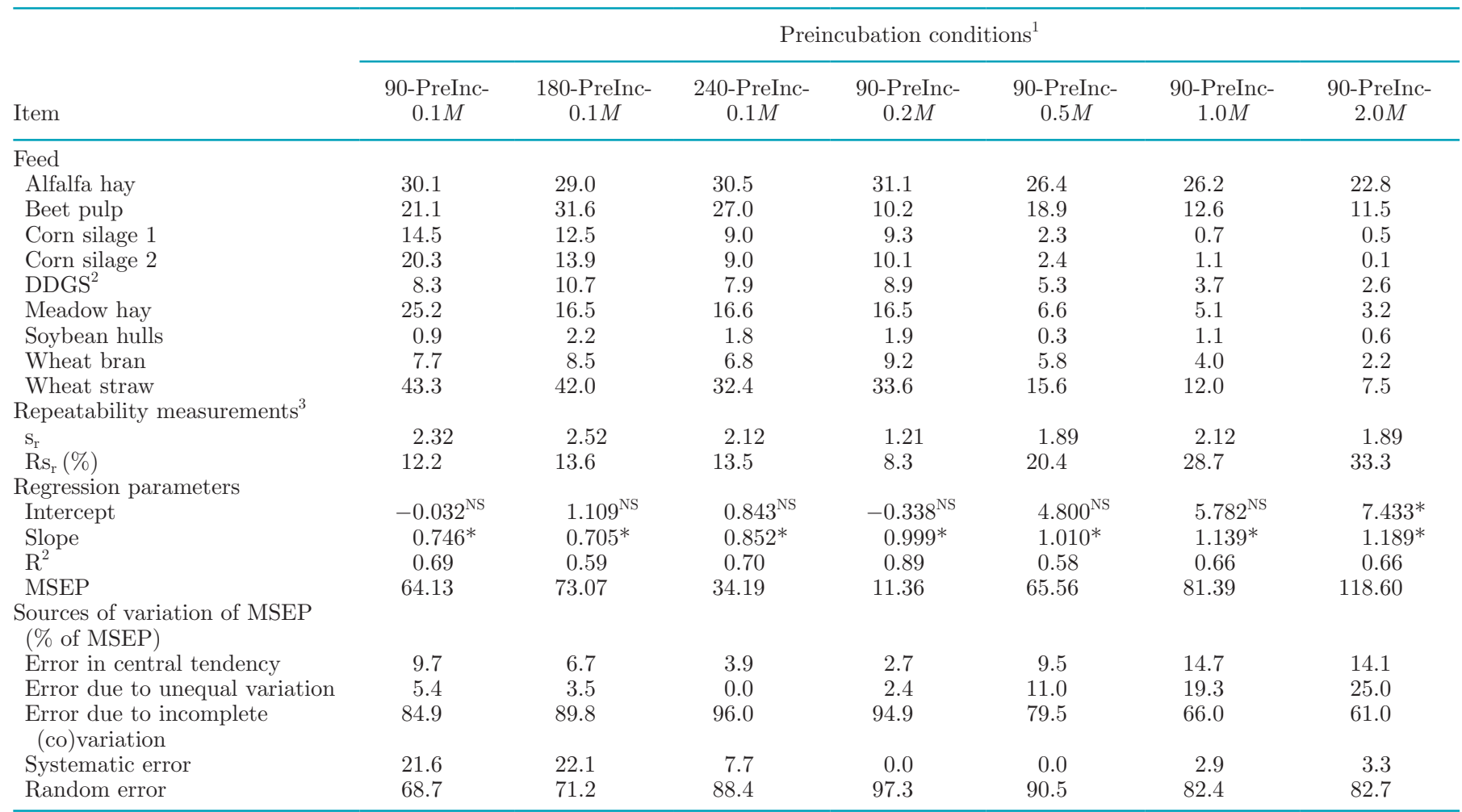

${ }^{1}$ The preincubation step consisted of incubating samples $(\sim 300 \mathrm{mg})$ in a $0.1 \mathrm{M} \mathrm{NaOH}$ solution $(15 \mathrm{~mL} / \mathrm{bag})$ for $90 \mathrm{~min}(90-\mathrm{PreInc}-0.1 \mathrm{M})$, $180 \mathrm{~min}(180-$ PreInc-0.1 $M$ ), or $240 \mathrm{~min}(240$-PreInc-0.1 $M$ ) or in $0.2 M \mathrm{NaOH}(90-$ PreInc-0.2 $M), 0.5 M \mathrm{NaOH}(90-\mathrm{PreInc}-0.5 M), 1.0 M \mathrm{NaOH}$ (90-PreInc-1.0M), or $2.0 \mathrm{M} \mathrm{NaOH}(90-P r e I n c-2.0 M$ ) for $90 \mathrm{~min}$. Then, samples were subjected to 2 successive steps of enzymatic incubation: (1) incubation in a buffered $(\mathrm{pH}$ 6) solution $(15 \mathrm{~mL} / \mathrm{bag})$ containing hemicellulase from Aspergillus niger, cellulase from Trichoderma viride, and Viscozyme L enzymes (Sigma-Aldrich s.r.l., Milan, Italy); and (2) incubation in a buffered (pH 5) solution (15 mL/bag) containing xylanase from Thermomyces lanuginosus.

${ }^{2}$ Distillers dried grains with solubles.

${ }^{3} \mathrm{~S}_{\mathrm{r}}=$ standard deviation of differences between repeated measurements; $\mathrm{Rs}_{\mathrm{r}}=$ coefficient of variation of $\mathrm{s}_{\mathrm{r}}$.

$* P<0.05$ : probability that regression parameters are equal to zero. 
Table 3. Regression parameters and sources of variation of the mean square errors of prediction (MSEP; DM $\left.{ }^{2}\right)$ of the multi-step enzymatic method $^{1}$ used to estimate in situ undigested NDF (uNDF, \% of DM) of all forages and of specific forage categories (mean \pm SD)

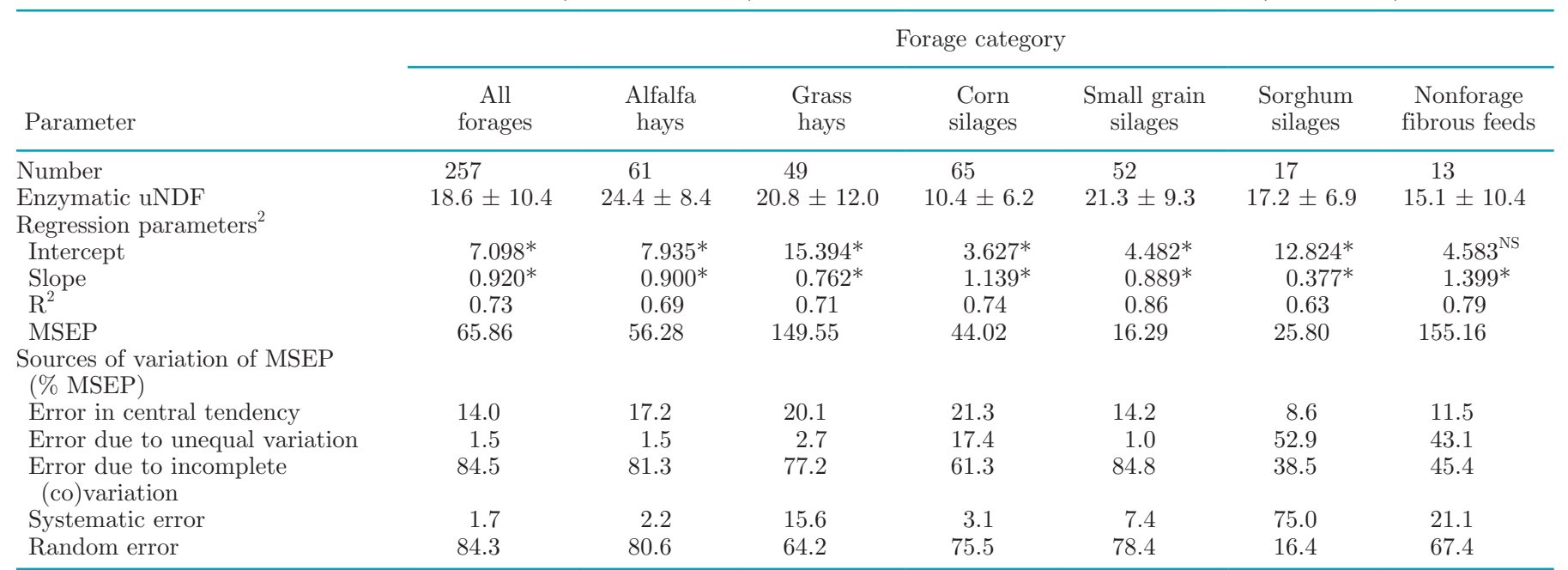

${ }^{1}$ The preincubation step consisted of incubating samples (approximately $300 \mathrm{mg}$ ) in a $0.2 \mathrm{M} \mathrm{NaOH}$ solution (15 mL/bag) for $90 \mathrm{~min}$. Then, samples were subjected to 2 successive steps of enzymatic incubation: (1) incubation in a buffered (pH 6) solution (15 mL/bag) containing hemicellulase from Aspergillus niger, cellulase from Trichoderma viride, and Viscozyme L enzymes (Sigma-Aldrich s.r.l., Milan, Italy); and (2) incubation in a buffered $(\mathrm{pH} 5)$ solution $(15 \mathrm{~mL} / \mathrm{bag})$ containing xylanase from Thermomyces lanuginosus.

${ }^{2} \mathrm{In}$ situ uNDF was the independent variable and enzymatic uNDF was the dependent variable of regression.

${ }^{*} P<0.05$ : probability that regression parameters are equal to zero.

nosus) for degradation of fiber fractions in the 2-step enzymatic procedure were discussed. This previous multi-step enzymatic method provided suitable estimates of in situ NDFD values for incubation times of 24 to $72 \mathrm{~h}$, but it was unable to accurately estimate in situ NDFD for rumen incubations $<18 \mathrm{~h}$ or $>96 \mathrm{~h}$. Consequently, we recommended further studies to improve the applicability of enzymatic method for estimating in situ measurements evaluated by long incubation times, such as uNDF. Another important result from the previous study (Gallo et al., 2017) was that the length of the alkaline pretreatment had a greater effect on fiber hydrolysis than the duration of enzymatic incubations for most of the 20 tested samples. Consequently, the present study focused on the PreInc phase by testing different durations of $0.1 \mathrm{M} \mathrm{NaOH}$ pretreatments and different concentrations of $\mathrm{NaOH}$. We identified the 90-PreInc- $0.2 M$ protocol as providing optimal performance in terms of repeatability and estimation of in situ uNDF.

Our enzymatic measurements of uNDF overestimated in situ uNDF, particularly for grass hays. Despite this, our method seems to have great promise for accurately estimating in situ uNDF of different forages, as shown previously by analyzing regression performance. Thus, the enzymatic approach described here could be used as an alternative to other methods currently used to quantify the uNDF of feedstuffs, such as in situ or in vitro rumen-based methods (Huhtanen et al., 2006; Bender et al., 2016) or NIRS (Brogna et al., 2018).
Several specific aspects of the method described here require further optimization to improve the accuracy of the estimates of uNDF, especially for sorghum silages and certain other feeds.

\section{ACKNOWLEDGMENTS}

Financial support was provided by Fondazione Romeo ed Enrica Invernizzi (Milan, Italy).

\section{REFERENCES}

AOAC International. 1995. Official Methods of Analysis. 16th ed. AOAC International, Washington, DC.

Bender, R. W., D. E. Cook, and D. K. Combs. 2016. Comparison of in situ versus in vitro methods of fiber digestion at 120 and 288 hours to quantify the indigestible neutral detergent fiber fraction of corn silage samples. J. Dairy Sci. 99:5394-5400. https://doi.org/ 10.3168/jds.2015-10258.

Brogna, N., A. Palmonari, G. Canestrari, L. Mammi, A. Dal Prà, and A. Formigoni. 2018. Technical note: Near infrared reflectance spectroscopy to predict fecal indigestible neutral detergent fiber for dairy cows. J. Dairy Sci. 101:1234-1239. https://doi.org/10 $.3168 /$ jds.2017-13319.

Colombatto, D., F. L. Mould, M. Bath, and E. Owen. 1999. Fibrolytic enzyme mixtures as an alternative to rumen fluid for assessing feed degradation kinetics in vitro. Page 27 in Proc. Br. Soc. Anim. Sci., Scarborough, UK. Cambridge University Press, Cambridge, UK.

Fustini, M., A. Palmonari, G. Canestrari, E. Bonfante, L. Mammi, M. T. Pacchioli, G. C. J. Sniffen, R. J. Grant, K. W. Cotanch, and A. Formigoni. 2017. Effect of undigested neutral detergent fiber content of alfalfa hay on lactating dairy cows: Feeding behavior, fiber digestibility, and lactation performance. J. Dairy Sci. 100:4475-4483. https://doi.org/10.3168/jds.2016-12266.

Gallo, A., T. Bertuzzi, G. Giuberti, M. Moschini, S. Bruschi, C. Cerioli, and F. Masoero. 2016. New assessment based on the use of 
principal factor analysis to investigate corn silage quality from nutritional traits, fermentation end products and mycotoxins. J. Sci. Food Agric. 96:437-448. https://doi.org/10.1002/jsfa.7109.

Gallo, A., G. Giuberti, S. Bruschi, P. Fortunati, and F. Masoero. 2017. Technical note: Relationship between in situ NDF degradability and enzymatic NDF hydrolysis in forages, nonforage fibrous feeds, and crop residues. J. Anim. Sci. 95:4172-4180. https://doi.org/10 $.2527 /$ jas2017.1630.

Gallo, A., M. Moschini, C. Cerioli, and F. Masoero. 2013. Use of principal component analysis to classify forages and predict their calculated energy content. Animal 7:930-939. https://doi.org/10 $.1017 /$ S1751731112002467.

Huhtanen, P., J. Nousiainen, and M. Rinne. 2006. Recent developments in forage evaluation with special reference to practical applications. Agric. Food Sci. 15:293-323. https://doi.org/10.2137/ 145960606779216317

Kowalski, Z. M., J. Ludwin, P. Górka, M. Rinne, M. R. Weisbjerg, and W. Jagusiak. 2014. The use of cellulase and filter bag technique to predict digestibility of forages. Anim. Feed Sci. Technol. 198:49-56. https://doi.org/10.1016/j.anifeedsci.2014.09.008.

Krämer, M., M. R. Weisbjerg, P. Lund, C. S. Jensen, and M. G. Pedersen. 2012. Estimation of indigestible NDF in forages and concentrates from cell wall composition. Anim. Feed Sci. Technol. 177:40-51. https://doi.org/10.1016/j.anifeedsci.2012.07.027.

Krizsan, S. J., L. Nyholm, J. Nousiainen, K. H. Südekum, and P. Huhtanen. 2012. Comparison of in vitro and in situ methods in evaluation of forage digestibility in ruminants. J. Anim. Sci. 90:3162-3173. https://doi.org/10.2527/jas.2011-4347.

Lee, C., and A. N. Hristov. 2013. Short communication: Evaluation of acid-insoluble ash and indigestible neutral detergent fiber as totaltract digestibility markers in dairy cows fed corn silage-based diets. J. Dairy Sci. 96:5295-5299. https://doi.org/10.3168/jds.2012 -6442 .

Mertens, D. R. 2016. Using uNDF to predict dairy cow performance and design rations. Pages 12-19 in Proc. Four-State Dairy Nutr. Manag. Conf., Dubuque, IA.

Nousiainen, J., M. Rinne, M. Hellämäki, and P. Huhtanen. 2003. Prediction of the digestibility of primary growth and regrowth grass silages from chemical composition, pepsin-cellulase solubility and indigestible cell wall content. Anim. Feed Sci. Technol. 110:61-74. https://doi.org/10.1016/S0377-8401(03)00206-2.
NRC. 2001. Nutrient Requirements of Dairy Cattle. 7th rev. ed. Natl. Acad. Sci., Washington, DC.

Palmonari, A., A. Gallo, M. Fustini, G. Canestrari, F. Masoero, C. J. Sniffen, and A. Formigoni. 2016. Estimation of the indigestible fiber in different forage types. J. Anim. Sci. 94:248-254. https:// doi.org/10.2527/jas.2015-9649.

Raffrenato, E., D. A. Ross, and M. E. Van Amburgh. 2018. Development of an in vitro method to determine rumen undigested aNDFom for use in feed evaluation. J. Dairy Sci. 101:9888-9900. https: //doi.org/10.3168/jds.2018-15101.

Rinne, M., A. Olt, J. Nousiainen, A. Seppälä, M. Tuori, C. Paul, M. D. Fraser, and P. Huhtanen. 2006. Prediction of legume silage digestibility from various laboratory methods. Grass Forage Sci. 61:354-362. https://doi.org/10.1111/j.1365-2494.2006.00542.x.

SAS Institute. 2003. Guide for Personal Computers, Version 9.2. SAS Inst. Inc., Cary, NC.

Spanghero, M., P. Berzaghi, R. Fortina, F. Masoero, L. Rapetti, C. Zanfi, S. Tassone, A. Gallo, S. Colombini, and J. C. Ferlito. 2010. Technical note: Precision and accuracy of in vitro digestion of neutral detergent fiber and predicted net energy of lactation content of fibrous feeds. J. Dairy Sci. 93:4855-4859. https://doi.org/ 10.3168/jds.2010-3098.

Tedeschi, L. O. 2006. Assessment of the adequacy of mathematical models. Agric. Syst. 89:225-247. https://doi.org/10.1016/j.agsy .2005.11.004.

Van Amburgh, M. E., E. A. Collao-Saenz, R. J. Higgs, D. A. Ross, E. B. Recktenwald, E. Raffrenato, L. E. Chase, T. R. Overton, J. K. Mills, and A. Foskolos. 2015. The Cornell Net Carbohydrate and Protein System: Updates to the model and evaluation of version 6.5. J. Dairy Sci. 98:6361-6380. https://doi.org/10.3168/jds.2015 $-9378$.

Van Soest, P. J., J. B. Robertson, and B. A. Lewis. 1991. Methods for dietary fiber, neutral detergent fiber, and nonstarch polysaccharides in relation to animal nutrition. J. Dairy Sci. 74:3583-3597.

Vanzant, E. S., R. C. Cochran, and E. C. Titgemeyer. 1998. Standardization of in situ techniques for ruminant feedstuff evaluation. J. Anim. Sci. 76:2717-2729. https://doi.org/10.2527/1998 $.76102717 x$ 